\title{
REPENSANDO A AVALIAÇÃO DA APRENDIZAGEM
}

RETHINKING THE LEARNING EVALUATION

\section{Rosangela Maria Fenili ${ }^{1}$ Maria Emilia de Oliveira ${ }^{1}$ Odalea M. Brüggemann dos Santos ${ }^{1}$ Elisabeta Roseli Eckert ${ }^{1}$}

\begin{abstract}
RESUMO: Este trabalho busca conhecer e compreender como o Curso de Graduação em Enfermagem da Universidade Federal de Santa Catarina (UFSC), avalia seus alunos. Analisa como a avaliação está estruturada nos planos de ensino de oito disciplinas do período profissionalizante. A partir da análise realizada percebe-se que as disciplinas utilizam como critério as notas, e todas atribuem pesos diferenciados para cada atividade, de acordo com critérios estabelecidos somente pelos professores. Assim, pode-se dizer que a prática "dita" como avaliação da aprendizagem, não passa de uma verificação. Neste sentido, as autoras apontam alguns caminhos que possam redirecionar esta prática.
\end{abstract}

PALAVRAS CHAVES: Avaliação; Ensino-Aprendizagem; Graduação; Enfermagem.

ABSTRACT: This study sought to know and understand how Nursing Graduation Course at Santa Catarina Federal University evaluates the students. It analyses how the evaluation is structured in teaching programs of eight subjects of professional period. From data analyses it is possible to observe that the subjects use as a criteria the marks and all of them attribute different levels to each activity, according to established criteria of the teachers. Thus, it can be said that what is "done" as learning evaluation is merely a verification. In this sense, the authors point out some ways that can redirect this practice.

KEY WORDS: Evaluation; Teaching-Learning; Graduation; Nursing.

\section{INTRODUÇÃO}

A avaliação norteia todo o viver da humanidade ao longo da sua trajetória. A exemplo, encontramos citações no Velho e Novo Testamento quando determina o certo e errado, o belo e o feio, o moral e amoral.

Todo esse processo é permeado de subjetividade, normas, condutas e códigos criados pelo homem.

$\mathrm{Na}$ área da educação a história se repete. $\mathrm{A}$ avaliação vem se constituindo em instrumento de aprovação/reprovação como uma prática, para se alçar ou não o saber e a ascensão social.

Segundo LUCKESI (1995), a avaliação tem sua origem na escola moderna com a prática de provas e exames que se sistematizou a partir do século XVI e XVII, com a cristalização da sociedade burguesa.

No século XVI a pedagogia jesuítica, apesar do rigor nos procedimentos para um ensino eficiente, buscando a construção de uma hegemonia católica, tinha uma atenção especial com o ritual das provas e exames. Estes, se caracterizavam por sessões solenes com formação de bancas examinadoras e comunicação pública dos resultados.

No século XVII a pedagogia comeniana, dá atenção à ação do professor como centro de interesse à educação, mas também utiliza os exames como forma de estímulo aos estudantes para o trabalho intelectual da aprendizagem.

Com o surgimento da burguesia, a pedagogia tradicional emergiu e se cristalizou, aperfeiçoando seus mecanismos de controle, destacando-se a seletividade escolar e seus processos de formação das personalidades dos educandos. A sociedade burguesa caracteriza-se pela exclusão e marginalização dos indivíduos que compõem a grande parcela da humanidade, sendo mecanismos imprescindíveis, o medo e o fetiche.

O termo avaliação da aprendizagem é recente, apareceu em 1930, e é atribuído a Ralph Tyler, educador norte americano que se dedicou à questão de um ensino que fosse eficiente.

Os pesquisadores norte-americanos da área de avaliação de aprendizagem definem o período de 1930 a 1945, como o período "tyleriano" da avaliação da aprendizagem.

O termo foi introduzido, mas a prática continuou sendo baseada em provas e exames, apesar de vários educadores acreditarem que a avaliação poderia e deveria subsidiar um modo eficiente de fazer ensino.

A prática de avaliação da aprendizagem que vem sendo desenvolvida nas nossas instituições de ensino nos remete a uma posição de poucos avanços. Não tem sido utilizada como elemento que

\footnotetext{
${ }^{1}$ Enfermeiras, Mestres, Docentes do Departamento de Enfermagem da Universidade Federal de Santa Catarina. Rua Eugênio Raulino Koerich, 619 - Bloco E - Apto 201 - Campinas - São José - SC CEP: 88101-060 - e-mail: fenili@nfr.ufsc.br
} 
auxilie no processo ensino aprendizagem, perdendose em mensurar e quantificar o saber, deixando de identificar e estimular os potenciais individuais e coletivos.

Buscando a compreensão do processo avaliativo no ensino, fomos procurar conceitos que pudessem nortear o nosso entendimento. Deparamonos com uma diversidade de opiniões, uma vez que o significado de avaliação, está relacionado com o modelo político pedagógico vigente.

Encontramos também o conceito de verificação, que no cotidiano das práticas educativas, tem sido utilizada como sinônimo de avaliação.

Para SORDI (1995), a prática de avaliação é um ato dinâmico onde o professor e o aluno assume o seu papel, de modo co-participativo, através da implementação do diálogo e da interação respeitosa, comprometendo-se com a construção do conhecimento e a formação de um profissional competente. É um ato essencialmente político, expressando concepções de Homem-MundoEducação.

No Dicionário Básico da Língua Portuguesa, FERREIRA (1995, p.205) refere que avaliação é um "Ato ou efeito de avaliar (-se). Apreciação, análise. Valor determinado pelos avaliadores. Avaliar é "determinar a valia ou valor de. Apreciar ou estimar o merecimento de. Calcular, estimar, computar. Fazer a apreciação; ajuizar: avaliar as causas, de merecimentos."

Por outro lado, LUCKESI (1995, p.69) entende "avaliação como um juízo de qualidade sobre dados relevantes, tendo em vista uma tomada de decisão". Estes são os elementos que compõem a compreensão constitutiva da avaliação.

Entende-se juízo como afirmações ou negações sobre alguma coisa, e juízo de qualidade expressa a qualidade do objeto que está sendo ajuizado, porém deve incidir sobre uma realidade atribuída ao objeto. O juízo de qualidade é produzido por um processo comparativo entre o objeto que está sendo ajuizado e o padrão ideal de julgamento.

O juízo de qualidade está fundamentado sobre os dados relevantes da realidade, a partir de caracteres do objeto (propriedades físicas); que no caso da aprendizagem são as condutas aprendidas e manifestadas pelos alunos. Se estas propriedades físicas não estiverem no processo de avaliação, pode-se cair no arbitrarismo, ou seja o professor qualifica ou desqualifica gratuitamente o aluno.

A tomada de decisão é uma tomada de posição, isto é, um estar a favor ou contra aquilo que foi julgado, sendo que isto implica em três possibilidades: continuar na situação, introduzir modificações ou suprimir a situação ou objeto. $\mathrm{Na}$ avaliação da aprendizagem, refere-se à decisão do que fazer com o aluno, quando a sua aprendizagem se manifesta satisfatória ou insatisfatória. Ao se desrespeitar esta etapa, o ato de avaliar não completará seu ciclo constitutivo.

HOFFMANN (1993), entende avaliação como uma ação provocativa do professor, desafiando o aluno a refletir sobre as experiências vividas, a formular e reformular hipóteses, direcionando para um saber enriquecido.

Já o termo verificação que tem sido amplamente utilizado, é referido por LUCKESI (1995), como aquele que emerge das determinações da conduta de, buscar "ver se algo é assim mesmo", investigar a verdade de alguma coisa. O processo de verificar compreende a observação, obtenção, análise e síntese dos dados ou informações que delimitam o ato com o qual se está trabalhando, encerrando-se com a configuração do objeto ou ato de investigação.

A diferença fundamental entre verificação e avaliação, é que a primeira é um ato estático e a segunda é um processo dinâmico e re-encaminha a ação.

Ao refletirmos sobre a condução do processo de avaliação surgem alguns questionamentos : por que o aluno não aprende ? A avaliação promove ou exclui o aluno? Os professores sabem avaliar? Qual o objetivo do processo de avaliação ?

As respostas para estas questões ainda se constituem em grandes desafios.

Percebemos que ela não tem sido utilizada como instrumento para aprendizagem, mas sim como fim em si mesmo. A avaliação na prática escolar, tem sido um mecanismo de conservação e reprodução da sociedade através do autoritarismo.

Nesta concepção, encontramos em LUCKESI (1995), alguns pontos que nos auxiliam a compreender estas questões. $\mathrm{O}$ ato de avaliar tem sido utilizado como forma de classificação e não como meio de diagnóstico, sendo que isto é péssimo para a prática pedagógica. A avaliação deveria ser um momento de "fôlego", uma pausa para pensar a prática e retornar a ela, como um meio de julgar a prática. Sendo utilizada como uma função diagnóstica, seria um momento dialético do processo para avançar no desenvolvimento da ação, do crescimento para a autonomia e competência. Como função classificatória, constitui-se num instrumento estático e freador do processo de crescimento, subtraindo do processo de avaliação aquilo que the é constitutivo, isto é, a tomada de decisão quanto à ação, quando ela está avaliando uma ação.

Desta forma, a avaliação desempenha um papel significativo para o modelo social liberalconservador, ou seja, o papel disciplinador. Os "dados relevantes" que devem ser considerados para o julgamento de valor, tornam-se "irrelevantes", sendo que o padrão de exigência fica ao livre arbítrio do professor. $O$ professor ao planejar suas atividades não estabelece o mínimo necessário a ser aprendido efetivamente pelo aluno, utilizando-se da "média" de notas, o que não expressa a competência do aluno, não permitindo a sua reorientação.

A média então, é realizada a partir da quantidade e não da qualidade, não garantindo o mínimo de conhecimento, (LUCKESI, 1995).

Esta prática torna a avaliação nas mãos do professor um instrumento disciplinador de condutas sociais, utilizando-a como controle e critério para aprovação dos alunos, buscando controlar e disciplinar, retirando destes a espontaneidade, 
criticidade e criatividade, transformando-os em "cordeiros" de um sistema autoritário e antipedagógico.

Surge então, o castigo escolar a partir do erro, apresentando-se de várias formas, desde agressões físicas, tão utilizadas no passado, assim como as morais e psicológicas presentes ainda hoje.

Concordamos com LUCKESI (1995), quando diz que o erro pode ser utilizado como fonte de virtude, sendo que o professor deve estar "aberto" para observar o acontecimento como acontecimento e não como erro. O insucesso deve servir de trampolim para o sucesso, nesse contexto, não significa erro. A compreensão do erro é o passo fundamental para a sua superação, servindo para reorientar seu entendimento e a prática. O erro não deve ser fonte de castigo, mas sim um suporte para sua compreensão, retirando dele os mais significativos benefícios.

Porém, o que predomina ainda hoje é a avaliação como instrumento do "medo" (controle social), gerando inseguranças e uma exacerbada submissão forçando o aluno a viver sob sua égide. Neste contexto, a avaliação encontra-se apoiada na "pedagogia do exame", voltada para a atenção na promoção e nas provas. Assim sendo, a atenção está centrada na nota e não no caminho percorrido para obtê-la, estas são operadas e manipuladas como se nada tivessem a ver com a trajetória do processo de aprendizagem. Os professores utilizam as provas como ameaça e tortura prévia, como um fator negativo de motivação. Os alunos são conduzidos a estudar, pensar e agir em função de uma nota e não pela obtenção do saber. O estabelecimento do ensino está estruturado com base nos resultados de provas e exames, assim a dinâmica do processo educativo permanece obnubilada pela supervalorização da avaliação centrada nas estatísticas das notas.

As conseqüências destas ações podem provocar nos avaliados, problemas pedagógicos, psicológicos e sociológicos, podendo desencadear várias doenças, sem contarmos com o constante stress que acometem os alunos e a família.
A aprendizagem neste contexto, deixa de ser algo prazeroso e solidário, passando a ser um processo solitário e desmotivador, contribuindo para a seletividade social, principalmente para atender as exigências do sistema econômico vigente.

Segundo HOFFMANN (1996, p.66) "Quando a finalidade é seletiva, o instrumento de avaliação é constatativo, prova irrevogável. Mas as tarefas, na escola, deveriam ter o caráter problematizador e dialógico, momentos de trocas de idéias entre educadores e educandos na busca de um conhecimento gradativamente aprofundado."

\section{OBJETIVOS}

- Conhecer e compreender como o Curso de Graduação em Enfermagem da UFSC vem avaliando seus alunos;

- Analisar como a avaliação está estruturada nos planos de ensino de oito disciplinas integrantes do período profissionalizante.

\section{DESENVOLVIMENTO}

O processo de avaliação configura-se como um perfeito arco- íris, uma vez que se apresenta com diferentes nuanças de cores, pois se trata de um processo de construção que comporta divergências, atitudes, crenças e valores enraizados na nossa cultura. Como nos diz a lenda do arco-íris, ao final do mesmo, há um pote de ouro, que aos nossos olhos é inatingível. $O$ processo de avaliação ideal, parece similar a este pote de ouro, porém poderemos alcançá-lo através da construção coletiva de um projeto político pedagógico. Ao lembrarmos da beleza e equilíbrio das cores do arco-íris, escolhemos algumas cores para representar as diversas disciplinas que serão analisadas.

Gostaríamos de ressaltar, que não foi nosso objetivo analisar os instrumentos de avaliação das atividades teórico-práticas utilizados nas disciplinas.

Os dados encontrados foram agrupados e organizados conforme mostramos a seguir:

\begin{tabular}{|c|c|c|c|}
\hline DISCIPLINA & COMO AVALIA & PESO & OBSERVAÇÕES \\
\hline Rosa & $\begin{array}{l}\text { Provas teóricas - } 04 \\
\text { Prova prática - } 01 \\
\text { Atividade de campo }\end{array}$ & $\begin{array}{l}5 \\
5\end{array}$ & \\
\hline Azul & $\begin{array}{l}\text { Provas teóricas - } 03 \\
\text { Trabalhos em forma de resumo }-02 \\
\text { Estudo com observação }-01 \\
\text { Seminário - } 01 \\
\text { Trabalho - } 01 \\
\text { Atividade teórico-prática: } \\
\text { Desempenho no campo } \\
\text { Prova teórico-prática } \\
\text { Trabalho - } 01\end{array}$ & $\begin{array}{c}3 \\
0,25 \\
0,25 \\
0,25 \\
0,25 \\
4 \\
1,5 \\
0,5\end{array}$ & $\begin{array}{l}\text { O aproveitamento das atividades práticas será medido } \\
\text { de forma integral, de acordo com o desenvolvimento } \\
\text { das atividades previstas para o alcance dos objetivos, } \\
\text { incluindo prova teórico-prática, relatório e evolução do } \\
\text { aluno nas atividades. Na atividade teórico-prática o } \\
\text { aluno procederá a sua auto-avaliação permanente e } \\
\text { continuamente, utilizando como referência o } \\
\text { instrumento de avaliação da fase. Haverá no mínimo } \\
\text { uma avaliação somativa/formativa, aluno/professor. O } \\
\text { resultado da avaliação somativa/formativa só será } \\
\text { conhecido pelo aluno se o mesmo for aprovado. Se o } \\
\text { aluno for reprovado, os resultados de um estágio } \\
\text { serão interdependentes com os demais, até a } \\
\text { superação das dificuldades do aluno. Nas faltas } \\
\text { justificadas os alunos terão oportunidade de repor o } \\
\text { conteúdo perdido. Faltas não justificadas implicam em } \\
\text { perda de conteúdo, podendo resultar em ausência de } \\
\text { cumprimento da atividade com nota zero. }\end{array}$ \\
\hline
\end{tabular}




\begin{tabular}{|c|c|c|c|}
\hline Verde & $\begin{array}{l}\text { Provas teóricas - } 03 \\
\text { Atividades teórico-práticas: } \\
\text { Estudo de situação - } 05 \\
\text { Seminários }-05 \\
\text { Fichas de leitura } \\
\text { Trabalhos - } 01 \\
\text { Atividades práticas: } \\
\text { Desempenho do aluno no campo } \\
\text { Provas no final de cada atividade prática }\end{array}$ & $\begin{array}{c}3 \\
0,5 \\
0,5 \\
0,5 \\
0,5 \\
4 \\
1\end{array}$ & $\begin{array}{l}\text { O aluno fará sua auto-avaliação continuada e } \\
\text { permanente utilizando o instrumento de avaliação da } \\
\text { área em que se encontra. Haverá no mínimo uma } \\
\text { avaliação somativa/formativa, aluno/professor. } \\
\text { aluno ao final das atividades teórico-práticas de cada } \\
\text { campo terá conhecimento do resultado da avaliação } \\
\text { somativa/formativa. }\end{array}$ \\
\hline Vermelho & $\begin{array}{l}\text { Avaliação formativa no período do conteúdo } \\
\text { teórico } \\
\text { Prova } \\
\text { Atividades teórico-práticas } \\
\text { Elaboração de planejamento }\end{array}$ & $\begin{array}{l}1,5 \\
2,0 \\
4,0 \\
2,5\end{array}$ & \\
\hline Violeta & $\begin{array}{l}\text { Prova teórica }-01 \\
\text { Relatório }-01 \\
\text { Seminário }-01 \\
\text { Relatório de atividade prática } \\
\text { Assiduidade e pontualidade } \\
\text { Compromisso }\end{array}$ & $\begin{array}{c}1 \\
0,5 \\
2,5 \\
5 \\
0,5 \\
0,5 \\
\end{array}$ & $\begin{array}{l}\text { Toda avaliação está descrita no instrumento de } \\
\text { avaliação de desempenho do aluno. }\end{array}$ \\
\hline Marrom & $\begin{array}{l}\text { Provas teóricas }-02 \\
\text { Atividades práticas: } \\
\text { Teste teórico-prático } \\
\text { Processo simplificado e/ou } \\
\text { específicos } \\
\text { Desempenho do aluno no campo }\end{array}$ & $\begin{array}{l}5 \\
5\end{array}$ & $\begin{array}{l}\text { Em todos os campos de atividades práticas serão } \\
\text { efetuados testes teórico-práticos. Haverá uma terceira } \\
\text { prova para os alunos que não obtiverem média } 6,0 \\
\text { nas duas primeiras provas, sendo que o peso das } \\
\text { duas primeiras provas será } 3 \text { e o da terceira } 2 \text {. O } \\
\text { aluno receberá uma nota ao final de cada campo de } \\
\text { atividade prática a partir da avaliação de desempenho } \\
\text { do aluno. }\end{array}$ \\
\hline Turquesa & $\begin{array}{l}\text { Projeto } \\
\text { Estágio } \\
\text { Relatório: } \\
\text { Trabalho escrito } \\
\text { Apresentação oral } \\
\text { Atitude profissional acadêmica: } \\
\text { Participação do aluno no grupo de trabalho }\end{array}$ & $\begin{array}{l}2 \\
4 \\
2 \\
1 \\
1\end{array}$ & $\begin{array}{l}\text { A avaliação será feita pelo professor, supervisor e } \\
\text { banca avaliadora do relatório com participação do } \\
\text { aluno. O projeto e relatório serão avaliados pela banca } \\
\text { avaliadora. O estágio será avaliado pelo orientador e } \\
\text { supervisor. }\end{array}$ \\
\hline
\end{tabular}

Analisando o exposto, percebemos nitidamente que os critérios de avaliação utilizados em todos os planos de ensino são apoiados em notas (peso), sendo que a distribuição dos mesmos não apresenta uma relação de valoração equilibrada para cada atividade. A exemplo, a atividade de seminário em alguns planos traz um valor tão baixo que acreditamos poder desmotivar os alunos para tal, visto que, a pedagogia utilizada é a da "nota".

Um dos planos refere que a avaliação será feita através do desempenho do aluno, entretanto a disciplina utiliza-se de provas para a avaliação. Encontramos aí uma contradição, visto que DILLY \& JESUS (1995), afirmam que na avaliação de desempenho utilizam-se relatórios e observações e na avaliação do rendimento escolar ou da aprendizagem, usualmente são utilizados instrumentos de medida sob a forma de testes escritos, provas orais e práticas.

No mesmo plano encontramos a existência de uma terceira prova, que será aplicada caso o aluno não atinja a média seis (6) esperada nas duas primeiras provas. Neste caso, é atribuído um valor super estimado para esta terceira prova. Segundo LUCKESI (1995), uma "oportunidade" da melhoria da nota, permitindo que faça uma nova aferição não significa que ocorra uma orientação para que o aluno estude a fim de aprender melhor, mas que estude tendo em vista a melhoria da nota.

Os conteúdos programáticos são traduzidos em objetivos específicos, sendo que alguns destes são exaustivamente detalhados, e trazem uma linguagem confusa e incompreensível para o aluno. Podemos citar um deles: Identificar grupos de risco segundo a vulnerabilidade, magnitude e transcendência. Será que o aluno compreende esta linguagem?

Ainda com relação aos objetivos, encontramos alguns extremos, sendo que em um plano, estão listados mais de cem objetivos e em outros menos de dez.

Um outro dado que nos leva à reflexão, é quando vemos em um dos planos, observações como a que segue : "O aluno deverá proceder à autoavaliação continuada e permanente utilizando como referência o instrumento de avaliação da área em que se encontra". Ora, sendo a auto-avaliação um processo que permite ao aluno fazer a avaliação do seu rendimento e de sua aprendizagem, surge aqui uma outra interrogação : Por que utilizar o instrumento como referência para a auto-avaliação ? Ao utilizá-lo, não estaremos criando redes para o controle?

Em relação ao instrumento de avaliação das atividades práticas, observamos que em alguns planos ele é citado, em outros não existe menção alguma. Acreditamos que todos possuam este instrumento, porém, a não referência no plano, deixa uma certa dúvida. Ao nosso ver, faz-se necessário descrevermos estas informações de forma legível e compreensível para alunos e professores, a fim de assegurarmos a transparência do processo.

Em um dos planos, aparece como observação : "Ao final das atividades teórico-práticas de cada campo (indivíduo, família e comunidade), o aluno terá 
conhecimento do resultado da avaliação pelo professor, salvo em caso de reprovação. Nesta situação os resultados do estágio serão interdependentes com os demais, até a superação das dificuldades do aluno". Aqui está evidenciado o poder do professor que se coloca numa atitude de reter as informações que se referem ao aluno e que somente ele tendo acesso a estas, poderá fazer sua autocrítica e melhorar o seu desempenho. Esta atitude "professoral", dá margem ao livre arbítrio do professor de conceder ou tirar as notas.

Nesse mesmo plano encontramos, referência a uma avaliação integrada, voltada para o aspecto do comportamento, atitude e evolução durante o desenvolvimento da disciplina. Entretanto, não esclarece quem participa da avaliação e o que significa o termo "integrado". Daí surge um questionamento : Será que o aluno participa deste momento?

Outro aspecto identificado é com relação à super valorização da presença do aluno no campo teórico- prático, pois a sua ausência não justificada implica em obter a nota zero (0), referente às atividades desenvolvidas naquele dia. O plano deixa de referendar se existe uma forma utilizada pelos docentes para recuperar o conteúdo e a nota nestes casos.

Notamos também, que em todos os planos de ensino não existe a uniformidade de linguagem ao tratar das questões ligadas à avaliação. $O$ que propomos é que seja mantida uma uniformidade dos termos sem contudo deixar de lado a similaridade específica de cada disciplina.

Encontramos ainda, observações do tipo : "Ao final das atividades teórico - práticas de cada campo, o aluno terá conhecimento do resultado da avaliação somativa/formativa efetuada pelo professor"; "Avaliação formativa no período do conteúdo teórico." Aqui perguntamos, o que é ser somativa/formativa no processo de avaliação ? Os termos somativa/formativa não foram explicitados no plano, levando-nos a buscar seu significado no senso comum. No Dicionário Básico da Língua Portuguesa, FERREIRA (1995, p.304), define formativo como "Que dá forma a alguma coisa"; e no Mini Dicionário LUFT (1995, p.303) formativo significa "Que dá forma", porém não encontramos a palavra "formativa". Com relação à palavra "somativa" não foi encontrado o seu significado nos dicionários.

No entanto, DILLY \& JESUS (1995) referem que avaliação formativa é utilizada para atender à função controladora que ocorre durante o processo de instrução e inclui os conteúdos importantes de uma etapa. Informa o professor e aluno sobre o rendimento da aprendizagem e localiza as deficiências na organização do ensino. Avaliação somativa é utilizada para atender à função classificatória no fim do processo ensino aprendizagem com a finalidade de classificar os alunos no fim do semestre ou ano, segundo níveis de aproveitamento. Visa a atribuição de notas e certificados e presta-se a comparação de resultados obtidos com diferentes alunos, materiais e métodos de ensino.

Encontramos também em um dos planos, que no processo avaliativo o professor orientador poderá solicitar maiores informações sobre o aluno, a partir de uma comissão de representantes docentes de fases anteriores que fornecerá informações acadêmicas do aluno, organizada pela coordenação de estágios. Entretanto, não deixa claro em que momento pode se dar esta solicitação, dando margem à má utilização deste recurso, uma vez que acreditamos que no final do processo este não servirá para reorientar o processo de aprendizagem.

Em nenhum dos planos avaliados foram traçados os objetivos mínimos a serem considerados nas várias etapas do processo avaliativo, por conseguinte, os alunos desconhecem que objetivos deverão atingir para o desenvolvimento de sua aprendizagem.

Não há como negar que na avaliação, as disciplinas usam como critério as notas e todas atribuem pesos diferenciados para cada atividade, dependendo do grau de valoração de cada uma, de acordo com critérios estabelecidos somente pelos professores. A avaliação da aprendizagem é feita de forma a classificar o aluno num certo estágio de desenvolvimento.

A partir desta análise, podemos dizer que a prática "dita" como avaliação da aprendizagem, não passa de uma verificação da aprendizagem. Como refere LUCKESI (1995), este fato fica patente na escola brasileira, quando observamos que os resultados da aprendizagem têm tido a função de estabelecer uma classificação do educando que se expressa em aprovação ou reprovação.

Todas as divergências, contradições e discrepâncias encontradas são conseqüentes da inexistência de um Projeto Político Pedagógico que contemple o processo de avaliação da aprendizagem.

\section{CONCLUSÃO}

Após conhecermos os fundamentos teóricos acerca do processo de avaliação, e analisarmos o item avaliação nos planos de ensino das diferentes disciplinas profissionalizantes do Curso de Graduação em Enfermagem da UFSC, possuímos alguns subsídios que nos permitem repensar e apontar caminhos para reconduzir à prática avaliativa.

LUCKESI (1995), refere que a sociedade que exige o controle e o enquadramento dos indivíduos nos parâmetros previamente estabelecidos para o "equilíbrio social" pratica a avaliação escolar dentro do modelo liberal conservador - autoritário, utilizando a avaliação como um instrumento disciplinador das condutas cognitivas e sociais.

Em contrapartida, nas pedagogias preocupadas com a transformação, a avaliação é utilizada como um mecanismo de diagnóstico da situação vislumbrando o avanço e o crescimento e não a estagnação disciplinadora. Sendo assim, para romper com o modelo de sociedade devemos romper com a pedagogia que o traduz. 
Para redirecionar a prática de avaliação faz-se necessário assumir um posicionamento pedagógico explícito, com um redimensionamento global das práticas pedagógicas de modo a orientá-la, no planejamento, na execução e na avaliação. Ao adotarmos um projeto pedagógico novo não podemos subestimar as seqüelas do velho, mas sim reconhecer a importância de seu impacto no perfil do profissional a ser formado.

Neste sentido, para que se dê um novo rumo à avaliação é necessário o resgate da sua função diagnóstica, ou seja, deverá ser um instrumento dialético do avanço, um instrumento de identificação de novos rumos. "Enfim, terá de ser o instrumento do reconhecimento dos caminhos percorridos e da identificação dos caminhos a serem perseguidos" (LUCKESI, 1995, p.43).

Diante dos grandes desafios que nos são impostos para tornar mais efetivo o processo de avaliação na área de enfermagem, devemos buscar medidas que nos levem a reformular a nossa prática avaliativa.

Sendo assim, ousamos apontar alguns caminhos que possam direcionar o nosso fazer dentro deste processo, que ainda se constitui como um desafio.

Sugerimos, que :

- seja dada transparência a professores e alunos dos eixos do projeto político pedagógico, encorajando-os a participar na sua consolidação e subsidiando-os para a definição do conteúdo necessário ao perfil profissional;

- o processo de avaliação seja diário e contínuo, pois através desta prática, os atores envolvidos podem sentir, de forma prática as melhorias a serem introduzidas para a aprendizagem;

- seja reforçado nos alunos a idéia do compromisso com o aprender, não se atendo apenas à nota. Deixar claro que esta é uma formalidade exigida pelo sistema, mas que a sua aferição dentro dos padrões mínimos, não garante que o conhecimento foi adquirido;

- os objetivos das disciplinas sejam traçados de maneira clara e compreensiva para alunos e professores, e que sejam propostos em número adequado a fim de que possam ser alcançados;

- a auto-avaliação seja um processo em que o aluno reflita sobre a sua aprendizagem, com responsabilidade e observando os objetivos da disciplina, mas sem redes para o controle;

- o instrumento de avaliação seja construído por professores e alunos, e que os mesmos estejam de acordo com os objetivos da disciplina;

- a prática avaliativa não seja solitária, e sim um compromisso professor/aluno, para que possa assim, traduzir as aspirações para a construção do sonho das grandes transformações;

- os professores busquem e percebam o valor da avaliação como instrumento para promoção e transformação do aluno, deixando de lado atitudes "policialescas" tão forte na nossa cultura avaliativa;
- a avaliação gere no aluno um desejo de busca e não um sentimento de derrota ou de produto acabado;

- os resultados do rendimento do aluno sejam devolvidos, garantindo-lhes atendimento individual para sanar suas dificuldades e reorientar a aprendizagem;

- sejam estabelecidos os conteúdos mínimos necessários, a serem adotados como referência para a avaliação;

- o professor ao reconhecer o erro cometido pelos alunos, utilize-o como instrumento para reorientar seus entendimentos e sua prática, possibilitando o aprimoramento e crescimento;

- a avaliação de atitudes (assiduidade, pontualidade, relacionamento, etc.) não sejam incorporadas no processo avaliativo através de mecanismos artificiais como nota, mas sim através de estratégias, definição de formas de orientação, discussões e avaliação conjunta do trabalho realizado. Esta internalização de atitudes poderá influir na formação e conseqüentemente na postura profissional;

- a terminologia utilizada nos planos de ensino seja uniforme, clara e objetiva, não utilizando "jargões" que o aluno não compreenda;

- sejam diversificadas as estratégias de avaliação, utilizando trabalhos e seminários como estímulo para a busca do conhecimento, não atribuindo pesos "irrelevantes" que poderão desestimular a realização dos mesmos;

- se faça "revisão de conteúdos" no início da disciplina, buscando resgatar conhecimentos adquiridos em etapas anteriores;

- seja formado um grupo de estudos sobre avaliação, permanecendo em contínuo processo de revisão e redimensionamento da sua prática.

Embora estejamos atrelados às tradicionais rotinas de aferir conceitos classificatórios impostos pelo nosso sistema de avaliação, acreditamos nas possibilidades de transformar os nossos sonhos cinzentos em coloridos.

Neste momento, Ihe convidamos a imaginar um novo cenário. Pense num dia cinzento e chuvoso, e ao abrir a janela você tem à sua frente um grande arco-íris. Certamente, você é levado a erguer os seus olhos e colocar-se a observar tamanha beleza. No início você busca identificar os matizes e as nuanças desta construção, mas, doce ilusão, ela lhe ofusca e você se perde na busca.

Estas cores que tanto buscamos e gostamos estão no nosso crer, estreitamente relacionadas com o projeto da avaliação, pois ele contém : beleza, harmonia, equilíbrio e prazer; é só uma questão de ver, sentir e agir.

Se você for mais curioso poderá levar a sua imaginação para um objeto que está no final do arcoíris, é lá que se depositam os grandes mistérios do saber e do ser da humanidade. A nossa expectativa é que neste local a humanidade possa encontrar as respostas para as grandes inquietações que permeiam o meu, o seu, enfim, o nosso viver. 


\section{REFERÊNCIAS BIBLIOGRÁFICAS}

DILLY, C. M. L.; JESUS, M.C.P. Processo educativo em enfermagem : das concepções pedagógicas à prática profissional. São Paulo : Robe, 1995.

FERREIRA, Aurélio. Dicionário Básico da Língua

Portuguesa. Rio de Janeiro : Nova Fronteira, 1995, p.304.

HOFFMANN, Jussara. Avaliação Mediadora: uma prática em construção da pré-escola à Universidade. 8. ed., Porto Alegre : Mediação, 1996.

LUCKESI, Cipriano C. Avaliação da aprendizagem escolar. São Paulo : Cortez, 1995.

LUFT, Pedro C. Mini Dicionário Luft. 8. ed. , São Paulo : Ática, 1995, p.303.

SORDI, Maria Regina de . A prática de avaliação do ensino superior : uma experiência na enfermagem. São Paulo: Cortez/PUCCAMP, 1995. 